\title{
Making rainfed crops adapted to potential climate change impacts: Modeling sustainable options
}

\author{
Youssef Brouziyne ${ }^{1 *}$, Abdelghani Chehbouni ${ }^{1,2}$, Aziz Abouabdillah ${ }^{3}$, Jamal Hallam $^{4}$, Fouad Moudden ${ }^{5}$, Ali El \\ Bilali $^{6}$, and Lahcen Benaabidate ${ }^{7}$ \\ ${ }^{1}$ Mohammed VI Polytechnic University, International Water Research Institute, Ben Guerir- Morocco \\ ${ }^{2}$ Institut de recherche pour le développement (IRD), unité mixte de recherche (UMR) Centre d'études spatiales de la \\ biosphère (Cesbio), Toulouse, France \\ ${ }^{3}$ National School of Agriculture, Meknes, Morocco \\ ${ }^{4}$ Soil and Water Management, Soil Health, National Institute for Agricultural Research-Agadir, Morocco \\ ${ }^{5}$ Department of Geology, Laboratory of Geo-engineering and environment, Research Group "Water Sciences \& \\ Environment Engineering", Faculty of Sciences, Moulay Ismail University, Meknes, Morocco \\ ${ }^{6}$ University Hassan II of Casablanca, Faculty of Sciences and Techniques of Moahammedia, Morocco \\ ${ }^{7}$ Laboratory of Functional Ecology and Environmental Engineering, Faculty of Sciences and Technology, University of Sidi \\ Mohamed Ben Abdellah, Fez, Morocco
}

\begin{abstract}
Rainfed agriculture is becoming increasingly vulnerable to climate change. This situation is expected to worsen under most future climate projections, which might increase the risks linked to food security and economies which depend on it. Providing insights about the potential responses of rainfed crops to climate change will helps on designing future adaptation strategies. In this study, large amount of data and the agro-hydrological model SWAT have been used to investigate future climate change impacts on rainfed wheat and sunflower crops in a semiarid watershed in Morocco (R'dom watershed). Downscaled CORDEX climate projections were used in generating future plants growth simulation for R'dom watershed in the 2031 to 2050 horizon under two Representative Concentration Pathways (RCPs): 4.5 and 8.5. The main results of climate change scenarios highlighted that R'dom watershed will undergo significant decrease in water resources availability with more impact under the scenario RCP 8.5 . Water productivities of both studied crops could be lower by up to $-21 \%$ in comparison with baseline situation. Different sustainable management strategies have been simulated using SWAT model under climate change context. The adopted approach succeeded in building up sustainable management strategies toward secured food security in the future.
\end{abstract}

\section{Introduction}

Globally, the projectedimpacts of climate change on agricultural productivity are an important concern for decision makers, investors and population. Global farming systems are supposed to support both current and future growing demand for food worldwide; thus, increasing productivity, especially for the mid and long term, should be led through the adaptation of agricultural systems to projected climate change [1]. Many development international agencies and organizations believe that there is still an opportunity to preserve ecosystem balances and are claiming for nature based and sustainable strategies to prepare farming activities to future climate impacts [2].

Rainfed agriculture was always playing crucial role in food security and social integrity for many populations around the world. This farming mode is representing around eighty per cent of the global agricultural lands, and is characterized by low yield levels and high vulnerability to climate effects [3]. Rainfed agriculture in Morocco is particularly vulnerable to the uneven spatiotemporal distribution of rainfall, and is expected to be more vulnerable to the projected climate change especially in arid and semi-arid areas; this problematic will inevitably put the national economy at risks [4].

\footnotetext{
${ }^{*}$ Correspondingauthor: Youssef.brouziyne@gmail.com
} 
Several crop growth models have proved their efficacy in miming the real crops development processes around the world, and are generally used to investigate crop's response under stressful conditions (temperature stress, water shortage, pests and weeds stress, restricted fertilization.). Most of these models are relying on a series of functions replicating biological and biophysical processes linking plants to their environments [5]. Some of these models are offering further options through their ability to simulating management strategies so as to investigate the effectiveness of cropping practices in tackling stressors impact (such as: climate change) [6].

Soil and Water Assessment Tool (SWAT), the used model in this study, is a semi-distributed model for physical processes (Hydrology, plants growth, solid transport....) that has been globally used in similar studies [7]. This tool helps in assessing the impact of phenomenon (Ex: Climate change), hydrological and conservation strategies, as well as the effect of agriculture practices [8].

The main purpose of this work is assessing rainfed crops' productivity in a semi-arid watershed, R'dom watershed, under two RCP scenarios (4.5 and 8.5) downscaled from a regional circulation model in the near future (2031 to 2050). SWAT model has been used to simulate a set of sustainable practices to build more resilient farming systems in the area. Results will help to understanding potential climate change impacts on strategic rainfed crops in a typical agro-forestry watershed in the Mediterranean area, and contribute to more adapted agricultural systems in any watershed similar to R'dom.

\section{Materials \& Methods}

\subsection{Study area}

Located in the north eastern of Morocco, and with a total drainage area of the $1993 \mathrm{~km}^{2}$, R'dom watershed includes two large plains (Saiss and Gharb). Being a part of one of the largest hydrologic watersheds in Morocco (Sebou basin), R'dom watershed is lying under a Semi-arid climate zone and hosts various socio-economic activities (ex: farming and forestry activities) (table 1).

Table 1. Occupation percentages of major land covers in R'dom watershed

\begin{tabular}{|c|c|c|}
\hline \multicolumn{2}{|c|}{ Land use categories } & Percentage (\%) \\
\hline \multicolumn{2}{|c|}{ Residential centre } & 3.69 \\
\hline \multicolumn{2}{|l|}{ Forest (Oak) } & 7.98 \\
\hline \multicolumn{2}{|l|}{ Pasture \& Barren } & 42.03 \\
\hline \multicolumn{2}{|l|}{ Wetlands/Lakes } & 1.71 \\
\hline \multirow{5}{*}{$\begin{array}{l}\text { Agricultural } \\
\text { lands }\end{array}$} & Wheat & 12.23 \\
\hline & Corn & 9.83 \\
\hline & Olive trees & 10.59 \\
\hline & Onion \& potatoes & 7.21 \\
\hline & Sunflower & 4.73 \\
\hline
\end{tabular}

\subsection{Model presentation}

SWAT is a physical-based modelthat operates through the division of the basin to several sub-basins and then to smaller sub-units called HRUs (Hydrologic Response Units) [9]. This disaggregation is based on soil types, topography, and land use classes in the study watershed. The model is then simulating the physical processes in each single HRU and gives chance to model management strategies at each HRU (and Sub-basin) level. [10]. In this study, water balance of R'dom watershed was studied at the basin outlet (Souk Elhadstreamgauge) where measured flow out data are available. SWAT is relying on EPIC model (Erosion Productivity Impact Calculator) [11] to simulateplantsgrowth process and to estimateyield. In SWATmodel, plant development is a function of: actual evapotranspiration, leaf area development, light interception and its conversion to biomass and yield. Plant growth can be limited by temperature, water, Nitrogen or Phosphorous stress. 


\subsection{Input data collection and preparation}

Being a very important step of any modeling work, data collection and preparation for this study was performed with high precision in order to run SWAT with a start conditions reflecting the reality as much as possible. As per the topographic of the study watershed, a $30 \mathrm{~m}$ digital elevation model (DEM) of R'dom basin has been extracted from the Shuttle Radar Topography Mission (SRTM) (Figure 1).

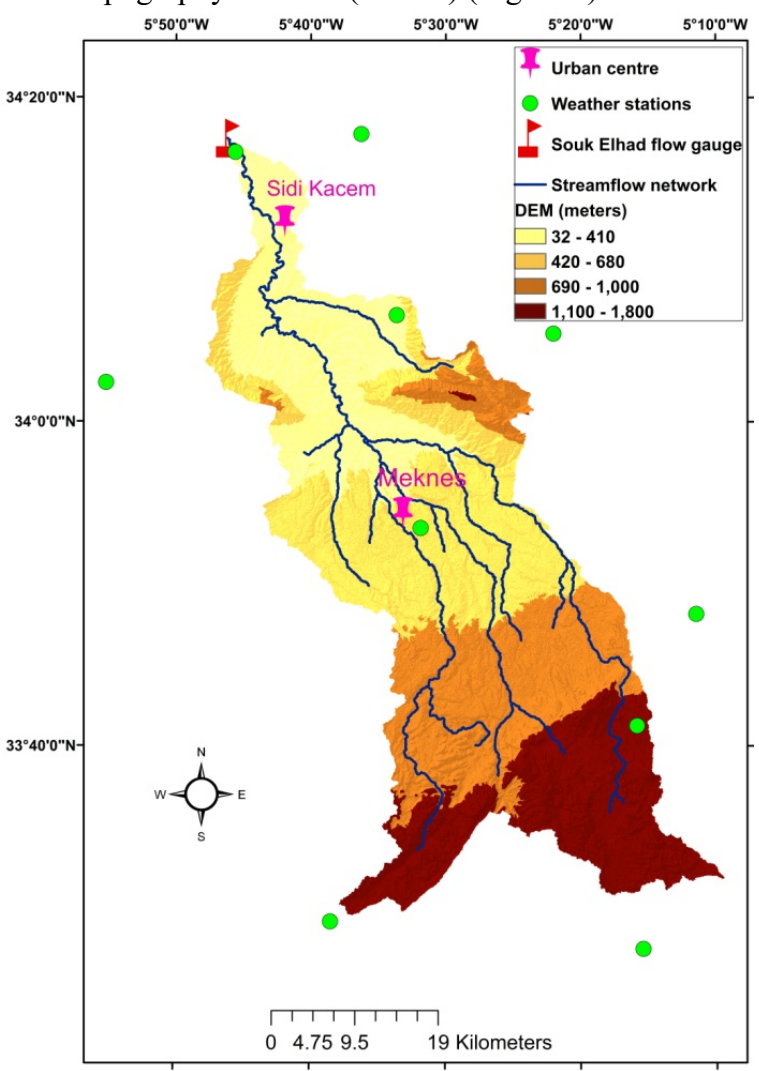

Fig.1. Digital elevation model of R'dom watershed

Soil database of SWAT model was fedby measured soil parameters of the studywatershed based on findings of a study performed by the Moroccan Minister of Agriculture on soil types of the area of Meknes-El Hajeb- Sidi Kacem (Soils study at 1/100,000 scale in the district of Meknes for agricultural development- June 1989). A couple of soil parameters (such as: Saturation hydraulic conductivity and Field capacity...) were estimated using a pedological transfer functions (Soil Water Characteristics software $C$, Version 6.02.74). Prior to rely on Soil Water Characteristics in estimating the missing parameters, the performances of this software were calibrated against the available soil parameters fromthe study performed by the Moroccan minister of agriculture such as the available water content.

A 30m land cover of R'dom basin was developed based on satellite image processing; after fields' surveys in the main catchment area to have preliminary insight about field situation, two LANDSAT8 image scenes (taken on $2^{\text {nd }}$ April 2015) were processed using ERDAS Imagine 2014 and ArcGIS 10.2.2. Supervised classification method was used by creating land use classes based on their respective spectral signals.

Observed weather parameters were imported to the SWAT and that included daily temperature (max and min) records and daily rainfall from 10weather stations located inside and around the study watershed (Figure 1). Weather datasetswere from January 2003 to December 2010.

Winter wheat and sunflower were chosen as target crops for this study. The conventional practices used are given in Table 2 [12-14]. Farming practices features were amended according to the real agronomic practices held in R'dom watershed, especially the operations that can have an effect on water cycle such as: season calendar, irrigation management, tillage machinery and frequency...etc (Table 2). In this study, optimal fertilization was supplied to crops so as not be considered a limitation factor to plant growth; only heat and water stress (due to potential climate change impact) were taken into account. 
Table 2. Considered farming patterns for winter wheat and sunflower

\begin{tabular}{|c|c|c|}
\hline Farming Practice & Winter wheat & Sunflower \\
\hline Sowing date & 1st November & 20th March \\
\hline Harvest date & 1st June & 1st July \\
\hline Tillage techniques & Chisel plow + Disk harrow & Disc plow + Disc harrow \\
\hline Fertilization N-P-K $(\mathrm{kg} / \mathrm{Ha})$ & $90-70-80$ & $110-30-40$ \\
\hline
\end{tabular}

Default crops database of SWAT is offering a wide generic characteristics of crops, in order to reflect the real crops behaviours against the study region conditions, some cultivar characteristics of the selected crops were amended based on previous studies [14-18](Table 3).

Table 3.Amended plants growth parameters in SWAT database for Wheat and Sunflower crops

\begin{tabular}{|l|l|c|c|c|c|}
\cline { 3 - 6 } \multicolumn{2}{c|}{} & \multicolumn{2}{c|}{ Winter Wheat } & \multicolumn{2}{c|}{ Sunflower } \\
\hline SWAT Parameters & default value & amended value & default value & amended value \\
\hline T base & Minimum T base $\left(\mathrm{C}^{\circ}\right)$ & 0 & 10 & 6 & 10 \\
\hline T opt & Optimal T for plant growth $\left(\mathrm{C}^{\circ}\right)$ & 18 & 20 & 25 & 25 \\
\hline EXT_COEF & Light extinction coefficient & 0.65 & 0.6 & 0.9 & 0.7 \\
\hline RDMX & Maximum root depth $(\mathrm{m})$ & 1.3 & 1 & 2 & 2.2 \\
\hline CHTMX & Maximum canopy height $(\mathrm{m})$ & 0.9 & 1.8 & 2.5 & 2.5 \\
\hline
\end{tabular}

\subsection{SWAT simulation}

Watershed outlet was manually added to match the geographic location of Souk El Had gauge (Figure 1), the selected station is where flow out process will be monitored to compare measured and predicted flows.

In overall,simulations were from January 2004 to December 2009, the very first two years have been dedicatedto warm up process, the period January 2006 to December 2007 was dedicated to model calibration. Validation was performed over the period January 2008 to December 2009.

SUFFI-2 algorithm [19] of the calibration and uncertainty program SWAT-CUP [20]was used to carry out calibration, validation and uncertainty analysis.

Streamflow and annual crops yields were monitoredduring the calibration and validation processes. Anoptimalgoodness-of-fitbetween observed and predicted water budget and yields components was the ultimate goal. This agreement was examinedby two parameters indicating the statistical indicators and the optimization of the objective functions of this study.

The used statistics tests are:

$$
\mathrm{NSE}=1-\frac{\sum_{\mathrm{i}=1}^{\mathrm{n}}(\mathrm{Oi}-\mathrm{Pi}) 2}{\sum_{\mathrm{i}=1}^{\mathrm{n}}\left(\mathrm{Oi}-\mathrm{O}_{\text {avg }}\right)^{2}}
$$

and:

$$
\mathrm{R}^{2}=\left(\frac{\sum_{\mathrm{i}=1}^{\mathrm{n}}\left(\mathrm{O}_{\mathrm{i}}-\mathrm{O}_{\mathrm{avg}}\right)\left(\mathrm{P}_{\mathrm{i}}-\mathrm{P}_{\mathrm{avg}}\right)}{\left[\sum_{\mathrm{i}=1}^{\mathrm{n}}\left(\mathrm{O}_{\mathrm{i}}-\mathrm{O}_{\mathrm{avg}}\right)^{2} \sum_{\mathrm{i}=1}^{\mathrm{n}}\left(\mathrm{P}_{\mathrm{i}}-\mathrm{P}_{\mathrm{avg}}\right)^{2}\right]^{0.5}}\right)^{2}
$$

With:

Oi : the recordedcomponent (yield or streamflow) for time period i

Pi: the simulated value for the same period

$\overline{\mathrm{O}}$ : the mean of recordedcomponent per time period

$\mathrm{n}$ : the number of time periods 
The maximum NSE value is 1.0 and occurs if predicted values are perfectly matching measured ones. The determination coefficient, $\mathrm{R}^{2}$, provides an idea about how well the correlation between observed and simulated values is [9].

\subsection{Future climate data \& model scenarios}

The used climate change scenarios in this study were generated from the output of the global climate model CNRM CM5 (Centre National de RecherchesMeteorologique) based on IPCC Assessment Report (AR5). There are 4 different types of Representative Concentration Pathways (RCPs): RCP 2.6, RCP4.5, RCP6.0 and RCP 8.5 that represent different alternatives of global development (Kim et al., 2013). The CNRM participated in the Coordinated Regional Climate Downscaling Experiment (CORDEX) with different Regional Climate Models (RCMs) [21].

In this study, the downscaled RCM CLMcom-CCLM and two RCPs (4.5 and 8.5) were used. Grid size was 12.5 $\mathrm{km}$ and the baseline was from January 1981 to December 2005. The future simulation period for both precipitations and temperature ( $\max$ and $\min$ ) was from January 2031 to December 2050. Linear scaling and variance scaling approaches were used during the bias correction in order to show some levels of bias against real measured precipitation and temperature data respectively.

\section{Results \& discussion}

\subsection{Future climate conditions}

The analysis of the downscaled RCM data showedthat the R'dom watershedwill undergorainfall and mean temperature increase in the period 2031 to 2050 underboth emission scenarios (table 4). In general, a cumulative decrease of annual rainfall by-172.9 $\mathrm{mm}$ and $-213.6 \mathrm{~mm}$ are expected under RCP4.5 and RCP8.5 respectively. Temperature increase is also expected $\left(+1.1^{\circ} \mathrm{C}\right.$ and $1.7^{\circ} \mathrm{C}$ respectively for $\mathrm{RCP} 4.5$ and $\left.\mathrm{RCP} 8.5\right)$. Winter, an important season for cereals, will be the most significantly affected with a major change of $+3.4^{\circ} \mathrm{C}$ in January.

Table 4.Precipitation and temperature changes in climate change scenarios

\begin{tabular}{|c|c|c|c|c|c|c|c|}
\hline & \multicolumn{3}{|c|}{ Precipitation (mm) } & \multicolumn{3}{|c|}{ Mean temperature $\left({ }^{\circ} \mathrm{C}\right)$} \\
\hline & & Baseline & RCP 4.5 & RCP 8.5 & Baseline & RCP 4.5 & RCP 8.5 \\
\hline \multirow{3}{*}{ Winter } & December & 93.13 & -50.2 & -48.9 & 10.8 & +0.6 & +0.3 \\
\hline & January & 58.84 & -32.0 & -43.8 & 9.74 & +3.4 & +3.4 \\
\hline & February & 57.69 & -26.0 & -32.4 & 11.21 & +2.2 & +2.5 \\
\hline \multirow{3}{*}{ Spring } & march & 49.81 & -10.4 & -23.9 & 13.44 & +0.7 & +0.3 \\
\hline & April & 39.19 & -7.4 & -10.7 & 16.12 & +0.0 & +0.5 \\
\hline & may & 25.91 & -21.5 & -21.4 & 19.43 & +0.7 & +2.0 \\
\hline \multirow{3}{*}{ Summer } & June & 12.39 & -4.1 & -8.3 & 23.64 & +1.4 & +3.4 \\
\hline & July & 1.69 & +1.1 & +2.2 & 27.57 & +0.0 & +2.3 \\
\hline & august & 2.69 & +2.5 & -1.8 & 27.57 & +1.6 & +1.3 \\
\hline \multirow{3}{*}{ Autumn } & September & 19.28 & -4.2 & -3.9 & 23.45 & +1.2 & +1.2 \\
\hline & October & 48.42 & -4.9 & 10.4 & 19.06 & +1.1 & +1.9 \\
\hline & November & 67.83 & -15.7 & -31.1 & 14.17 & +0.1 & +1.0 \\
\hline & & 476.9 & -172.9 & -213.6 & 18.2 & +1.1 & +1.7 \\
\hline & & \multicolumn{3}{|c|}{ Totals } & \multicolumn{3}{|c|}{ Averages } \\
\hline
\end{tabular}




\subsection{SWAT Model calibration}

Calibration and validation efforts of SWAT model over R'dom watershed have been achieved as soon as the optimal goodness-of-fit between simulated and observed streamflow was achieved; the goodness-of-fit is when both R2 and NSE values are exceeding 0.5 [8].

Prior to calibration, sensitivity analysis was carried out for both hydrological and crops modules of SWAT. The identified influential parameters of both modules were adjusted using SWAT CUP to reach the best agreement between simulated and recorded process. The most influential parameters for hydrologic component of R'dom are: revealed that CN2 (Initial SCS runoff curve number for moisture condition II), SOL AWC (Available water capacity of the soil layer), ESCO (Soil evaporation compensation factor), and GWQMN (Threshold depth of water in shallow aquifer for return flow to occur). The most influential parameters for plants growth in R'dom watershed are: HVSTI (Harvest index), WSYF (Lower limit of HVSTI), and BLAI (Maximum potential leaf area index).

After adjusting all the influential parameters for hydrology, R2 and NSE values were respectively 0.85 and 0.68 in calibration, and 0.79 and 0.58 after validation. As per plant growth component, and since only R2 was used, its value was 0.65 in calibration and 0.6 for the validation for wheat and 0.7 in calibration and 0.66 for the validation.

\subsection{Future Water balance and crops performances}

Running SWAT model in R'dom watershed using future climate variables allowed the investigation of future water resources and crops performances in the study area; table 5 represent both values and changes of future crops water productivities and water yield from baseline situation.

Table 5. Average values of future crops water productivity and water yield, and their changes to baseline

\begin{tabular}{|l|l|c|c|c|}
\cline { 3 - 5 } \multicolumn{2}{c|}{} & Wheat CWP $\left(\mathbf{k g} / \mathbf{m}^{3}\right)$ & Sunflower CWP $\left(\mathbf{k g} / \mathbf{m}^{3}\right)$ & Water yield $(\mathbf{m m})$ \\
\hline \multirow{2}{*}{ RCP4.5 } & Values average & 0.56 & 0.32 & 71.17 \\
\cline { 2 - 5 } & Change to Baseline & $-18.8 \%$ & $-15.7 \%$ & $-20.2 \%$ \\
\hline \multirow{2}{*}{ RCP8.5 } & Values average & 0.54 & 0.21 & 65.67 \\
\cline { 2 - 5 } & Change to Baseline & $-21.7 \%$ & $-44.7 \%$ & $-26.4 \%$ \\
\hline
\end{tabular}

A clear decline of crop water productivities of both crops (wheat and sunflower) and water yield in the R'dom watershed is expected under both climate change scenarios. The extent of change is clearer under the pessimistic scenario for both crops and for the water resources too.

\subsection{Adaptation strategies}

In order to investigate potential adaptation opportunities of wheat and sunflower to climate change in R'dom watershed, a set of sustainable management strategies were simulated using the calibrated SWAT model over the study area and using the projected climate variables under RCP4.5 and RCP8.5. The selected adaptation strategies were built from the combination of three cropping techniques: No tillage, Early sowing by 10 days and by 20 days from the standard sowing date adopted by local farmers.

In overall, 5 different combinations of adaptations strategies were considered: No tillage (NT), 10 and 20 early sowing days (ESD-10 and ESD-20 respectively), and a combination of no tillage and sowing dates change: NT+ESD-10 and NT+ESD-20. While simulating the adaptation strategies, future total water yield (WYLD) was monitored too as we believe that adapting crops to climate change should not be at the expense of local water resources.

After running SWAT model using the selected adaptation strategies (separately), an analysis of the change to baseline scenario has been carried out; the table 6 represent simulation results. 
Table 6.average values and changes from baseline of crops water productivity and water yield after simulation of the adaptation strategies

\begin{tabular}{|c|c|c|c|c|c|c|}
\hline & \multicolumn{3}{|c|}{ RCP4.5 } & \multicolumn{3}{|c|}{ RCP8.5 } \\
\hline & $\begin{array}{c}\text { Wheat CWP } \\
\left(\mathrm{kg} / \mathrm{m}^{3}\right)\end{array}$ & $\begin{array}{c}\text { Sunflower CWP } \\
\left(\mathrm{kg} / \mathrm{m}^{3}\right)\end{array}$ & $\begin{array}{c}\text { WYLD } \\
(\mathrm{mm})\end{array}$ & $\begin{array}{c}\text { Wheat CWP } \\
\left(\mathrm{kg} / \mathrm{m}^{3}\right)\end{array}$ & $\begin{array}{c}\text { Sunflower CWP } \\
\left(\mathrm{kg} / \mathrm{m}^{3}\right)\end{array}$ & $\begin{array}{c}\text { WYLD } \\
(\mathrm{mm})\end{array}$ \\
\hline \multicolumn{7}{|c|}{ a. Comparison of indicators in BAU to baseline scenario } \\
\hline BAU & 0.56 & 0.32 & 71.17 & 0.54 & 0.21 & 65.67 \\
\hline Change (\%) & $-18.8 \%$ & $-15.7 \%$ & $-20.2 \%$ & $-21.7 \%$ & $-44.7 \%$ & $-26.4 \%$ \\
\hline \multicolumn{7}{|c|}{ b. Comparison of indicators in no tillage strategy to BAU scenario } \\
\hline NT & 0.68 & 0.50 & 71.7 & 0.63 & 0.33 & 66 \\
\hline Change (\%) & $+21.4 \%$ & $+56.3 \%$ & $+7 \%$ & $+16.7 \%$ & $+57.1 \%$ & $+5 \%$ \\
\hline \multicolumn{7}{|c|}{ c. Comparison of indicators in 10 and 20 days early sowing strategies to BAU scenario } \\
\hline ESD-10 & 0.64 & 0.33 & 72.57 & 0.62 & 0.20 & 66.8 \\
\hline Change (\%) & $+14.3 \%$ & $+3.1 \%$ & $+2 \%$ & $+14.8 \%$ & $-4.8 \%$ & $+1.70 \%$ \\
\hline ESD-20 & 0.59 & 0.19 & 73.9 & 0.5 & 0.16 & 67.9 \\
\hline Change (\%) & $+5.4 \%$ & $-40.6 \%$ & $+3.80 \%$ & $-7.4 \%$ & $-23.8 \%$ & $+3.40 \%$ \\
\hline \multicolumn{7}{|c|}{ d. Comparison of indicators in no tillage combined with 10 or 20 days early sowing strategies to BAU scenario } \\
\hline NT+ESD-10 & 0.70 & 0.33 & 72.21 & 0.64 & 0.21 & 67 \\
\hline Change (\%) & $+25.0 \%$ & $+3.1 \%$ & $+1.50 \%$ & $+18.5 \%$ & $0.0 \%$ & $+2 \%$ \\
\hline NT+ESD-20 & 0.56 & 0.19 & 74.01 & 0.52 & 0.16 & 69.88 \\
\hline Change (\%) & $0.0 \%$ & $-40.6 \%$ & $+4 \%$ & $-3.7 \%$ & $-23.8 \%$ & $+6.40 \%$ \\
\hline
\end{tabular}

Based on these results, both adapting wheat and sunflower crops and preserving water resources in R'dom watershed to future climate change is possible. Most of the simulated adaptation strategies gave good results on at least one variable; and some strategies leaded to inconsistent results across the parameters and the scenarios. Generally, the no tillage (NT), sowing earlier by 10 days (ESD-10), and no tillage and sowing earlier with 10 days (NT+ESD-10) gave the most consistent (positive) change over the three parameters and under the both RCPs.

\section{Conclusion}

This study attempts to investigate potential opportunities to curtail the vulnerability of two of key rainfed crops in Morocco to future climate change impacts. Results showed that SWAT model succeeded in replicating responses of both hydrology processes and crops development occurring in the study area; both processes will undergo significant effects of climate under both scenarios (RCP4.5 and RCP8.5).

The simulated sustainable adaptation strategies showed promising results as water resources' preservation and increase of crops water productivity is possible according to our SWAT's simulations over R'dom watershed conditions. Among the simulated strategies, no tillage one gave the best compromise between crops productivity, water use efficiency and water resources in the watershed. In the meanwhile, sowing 10 days earlier than usually offers good overall effectiveness to overcome the climate change impacts in the future; combining this strategy with no tillage, gives very promising results as well.

\section{References}

1. Y. Brouziyne, A. Abouabdillah, A. Hirich, R. Zaaboul, L. Benaabidate, Agr. Syst.162, 154-163, (2018)

2. R. Mrabet, Exp. Agr.38, 237-248, (2001)

3. R. Mrabet, R. Moussadek, A. Fadlaoui, E. Van Ranst, Field. Crop. Res.132, 84-94, (2012)

4. F. Zahour, M.A. Malik, R. Anser, M. Shehzad, A. Saleem, M. Anser, M. Siddiqui, K. Mubeen, S.H. Raza, CercetariAgronomice in Moldova, XLVIII, (2015)

5. P. Steduto, T.C. Hsiao, E. Fereres, D. Raes, In FAO Irrigation and Drainage Paper, (FAO Publications: Rome), (2012) 
6. H. Briak, R. Mrabet, R.Moussadek, K. Abouamaria, Int. Soil. Water. Conserv. Res.7, 176183,(2019)

7. J.G. Arnold, R. Srinivasan, R.S. Muttiah, J.R. Williams, J. Am. Water.Resour. As.34, 73-89, (1998)

8. D.N. Moriasi, J.G. Arnold, M.W. Van Liew, R.L. Binger, R.D. Harmel, T. Veith, T. ASABE,50, 885-900, (2007)

9. J.G. Arnold,;D.N. Moriasi,; P. Gassman; K.C. Abbaspour; M.J. White,; R. Srinivasan,; C. Santhi,; R.D. Harmel,; A. Van Griensven,; M.W. Van Liew, ASABE,55, 1491-1508, (2012)

10. K.C. Abbaspour, E. Rouholahnejad, S. Vaghefi, R. Srinivasan, H. Yang, B. Kløve, J. Hydrol.524, 733-752, (2015)

11. S.L. Neitsch, J.G. Arnold, J.R. Kiniry, J.R. Williams, K.W. King, Grassland, Soil and Water Research Laboratory-Agricultural Research Service, (Temple-Texas, US)76502, (2002)

12. A. Ait Houssa, L. Oubaki, K. Reda-Fathmi, S. Drissi, M. Lamghari, M. Benbella, H. Chraibi, Moroccan Minister of Agriculture: Rabat, (2014).

13. A. Bamouh, In Transfert de Technologie en Agriculture-PNTTA, (Agriculture, M.M.o., Rabat), 44, (1993)

14. A. Si Bennasseur, Fellah-trade. (2014)

15. A. Aboudrar, A. Bouaziz, P. Debaek, H. Chekli, In Proceedings of International Sunflower Conference, Fargo, USA, (2014)

16. J.S. Zwart, University of Delft, Delft, (2010).

17. M. Jlibene, In La creationgenetique a l'INRA:Methodologie, acquis et perspectives, (INRA, Ed. Institut National de Recherche Agronomique: Rabat), 57-97, (2009)

18. K.C. Abbaspour, C.A. Johnson, M.T. Van Genuchten, Vadose. Zone. J.3, 1340-1352, (2004)

19. K.C. Abbaspour, M. Vejdani, S. Haghighat, In Proc. Intl. Congress on Modelling and Simulation (MODSIM 07),1603-1609, (2007)

20. A. Dosio, Clim. Dynam.49, 493-519, (2017) 